\title{
Ignicoccus hospitalis and Nanoarchaeum equitans: ultrastructure, cell-cell interaction, and 3D reconstruction from serial sections of freeze-substituted cells and by electron cryotomography
}

\author{
Benjamin Junglas $\cdot$ Ariane Briegel $\cdot$ \\ Tillmann Burghardt $\cdot$ Paul Walther $\cdot$ Reinhard Wirth $\cdot$ \\ Harald Huber $\cdot$ Reinhard Rachel
}

Received: 13 March 2008 / Revised: 16 June 2008 / Accepted: 18 June 2008 / Published online: 12 July 2008

(C) Springer-Verlag 2008

\begin{abstract}
Ultrastructure and intercellular interaction of Ignicoccus hospitalis and Nanoarchaeum equitans were investigated using two different electron microscopy approaches, by three-dimensional reconstructions from serial sections, and by electron cryotomography. Serial sections were assembled into 3D reconstructions, for visualizing the unusual complexity of I. hospitalis, its huge periplasmic space, the vesiculating cytoplasmic membrane, and the outer membrane. The cytoplasm contains fibres which are reminiscent to a cytoskeleton. Cell division in I. hospitalis is complex, and different to that in Euryarchaeota or Bacteria. An irregular invagination of the cytoplasmic membrane is followed by separation of the two
\end{abstract}

Communicated by Erko Stackebrandt.

Electronic supplementary material The online version of this article (doi:10.1007/s00203-008-0402-6) contains supplementary material, which is available to authorized users.

B. Junglas $\cdot$ T. Burghardt $\cdot$ R. Rachel $(\bowtie)$

Centre for Electron Microscopy,

Faculty for Biology and Preclinical Medicine,

University of Regensburg, Universitätsstraße 31,

93053 Regensburg, Germany

e-mail: reinhard.rachel@biologie.uni-r.de;

reinhard.rachel@biologie.uni-regensburg.de

Present Address:

B. Junglas

The Institute of Anatomy, University of Regensburg,

Universitätsstraße 31, 93053 Regensburg, Germany

\section{A. Briegel}

Department of Molecular Structural Biology,

Max-Planck-Institute for Biochemistry,

82152 Martinsried, Germany cytoplasms. Simultaneous constriction of cytoplasmic plus outer membrane is not observed. Cells of $N$. equitans show a classical mode of cell division, by constriction in the midplane. Their cytoplasm exhibits two types of fibres, elongated and ring-shaped. Electron micrographs of contact sites between I. hospitalis and N. equitans exhibit two modes of interaction. One is indirect and mediated by thin fibres; in other cells the two cell surfaces are in direct contact. The two membranes of I. hospitalis cells are frequently seen in direct contact, possibly a prerequisite for transporting metabolites or substrates from the cytoplasm of one cell to the other. Rarely, a transport based on cargo vesicles is observed between I. hospitalis and N. equitans.

Present Address:

A. Briegel

Division of Biology, California Institute of Technology,

1200 East California Boulevard, Pasadena, CA 91125, USA

P. Walther

Central Unit Electron Microscopy,

University of Ulm, Albert-Einstein-Allee 11, 89069 Ulm, Germany

R. Wirth $\cdot$ H. Huber

Institute for Microbiology, University of Regensburg,

Universitätsstraße 31, 93053 Regensburg, Germany 
Keywords Crenarchaeota - Ignicoccus hospitalis . Nanoarchaeum equitans $\cdot$ Ultrastructure . 3D reconstruction - Serial sections $\cdot$ Cytoskeleton . Cell-cell interaction

$\begin{array}{ll}\text { Abbreviations } \\ \text { 3D } & \text { Three-dimensional } \\ \text { TEM } & \text { Transmission electron microscopy } \\ \text { FEG } & \text { Field emission gun } \\ \text { ECT } & \text { Electron cryotomography } \\ \text { AOUH } & \text { Acetone-osmiumtetroxid-uranylacetate- } \mathrm{H}_{2} \mathrm{O} \\ \text { EGFU } & \text { Ethanol-glutaraldehyde-formaldehyde-urany- } \\ & \text { lacetate }\end{array}$

\section{Introduction}

The current opinion of microbiologists on the lifestyle of prokaryotes changed significantly since the inception of the field. Historically, a single cell was thought to interact with the surrounding environment-liquid, cells, surfaces-on its own. Subsequently it became clear that prokaryotic cells interact with each other and today we know that their predominant state of being is inside microbial communities. One of the most unique interactions known so far is the specific interaction of two archaeal species, with Ignicoccus hospitalis (Paper et al. 2007) acting as host organism for Nanoarchaeum equitans (Huber et al. 2002; Jahn et al. 2008). Together with I. islandicus and I. pacificus (Huber et al. 2000), I. hospitalis belongs to the crenarchaeal genus Ignicoccus. All members are chemolithoautotrophs, using exclusively molecular hydrogen as electron donor for the reduction of elemental sulphur. I. hospitalis has the smallest genome of all axenic Archaea known today, $\sim 1.4 \mathrm{Mbp}$ only (http://imgweb.jgi-psf.org/cgi-bin/w/main.cgi). Recent results unravelled an important part of the physiology of I. hospitalis, its unique way of $\mathrm{CO}_{2}$ fixation (Jahn et al. 2007; Huber et al. 2008). In addition, cells of all three Ignicoccus species possess a cell envelope with unusual features: they lack any rigid cell wall component, like S-layer or pseudomurein, as found in many other Archaea described today (König et al. 2007). Ultrathin sections studied by transmission electron microscopy (TEM) show that the cells are surrounded by two membranes in a unique arrangement: the cytoplasmic membrane appears wavy, and vesicles bleb off from the cytoplasmic membrane into the periplasm, or are taken up into the cytoplasm (Rachel et al. 2002; Näther and Rachel 2004; Paper et al. 2007). The periplasm has a variable width of 20 up to $500 \mathrm{~nm}$ and contains round or elongated vesicles, each surrounded by a lipid membrane. The outer delineation of the periplasm and of the whole cell is an outer membrane, consisting of archaeal isoprenyl diether lipids (Jahn et al. 2004) and of multiple $\left(\sim 10^{5}-10^{6}\right)$ copies of a thermostable, pore-forming oligomer of a membrane protein; the mass of the monomer is $6.23 \mathrm{kDa}$ only (Burghardt et al. 2007). The cell envelope, and therefore its components, like lipids and proteins, is involved in the lifestyle of I. hospitalis, i.e. the uptake of the basic nutrients, $\mathrm{H}_{2}, \mathrm{CO}_{2}$, elemental sulphur, and ions. They are also assumed to play key role in the specific cell-cell interaction with the potential 'symbiont', $N$. equitans, either in mediating the contact, and/or in transporting metabolites in one or both directions. This is supported by facts known about the 'symbiont' $N$. equitans: The cells cannot be cultivated alone but only in the presence of and in contact with living I. hospitalis cells. With only $\sim 0.49 \mathrm{Mbp}$, the $N$. equitans genome is the smallest of all Archaea known today; it lacks genes for the biosynthesis of lipids, amino acids, nucleotides and cofactors (Waters et al. 2003). There is experimental evidence that lipids (Jahn et al. 2004) and amino acids (Jahn et al. 2008) are transported from I. hospitalis to N. equitans.

The basis for understanding the cell-cell interaction is an ultrastructural characterization of the cells, including the site of contact, in three dimensions. Such data exist for Archaea only in few cases. A direct interaction between halobacterial cells was reported (Rosenshine et al. 1989) to mediate the exchange of chromosomal DNA; the resolution of the scanning electron micrographs was, however, to low to show structural details. Two other modes for indirect cell-cell contacts are known: cells of Pyrococcus furiosus are interconnected via cable-like structures each made up of about 40-50 flagella (Näther et al. 2006); their function and the substances which might be exchanged are under investigation. For the hyperthermophile Pyrodictium, another framework for cell-cell contact and, possibly, intercellular transport of solutes was described: the cannulae, an extracellular protein network of hollow tubules, were shown to interconnect the periplasmic spaces of individual cells, using dual-axis electron cryotomography (ECT; Nickell et al. 2003).

For I. hospitalis and N. equitans, early data suggested a direct contact via their cell surfaces (Huber et al. 2002); structural details were obscured due to technical limitations. Later, the periplasmic vesicles of I. hospitalis were suggested to be part of a mechanism to supply cell components to N. equitans (Waters et al. 2003) but no structural data were provided. In order to elucidate the ultrastructure of I. hospitalis and N. equitans, we have, therefore, employed ECT, which is, nowadays, the method of choice for a 3D reconstruction of single cells (for reviews, see Frank 1992; McIntosh et al. 2005; Lucic et al. 2005; Jensen and Briegel 2007), and which provided spectacular results (Medalia et al. 2002; Scheffel et al. 2006; Briegel et al. 2006). Considering that the average diameter of I. hospitalis cells of 2-3 $\mu \mathrm{m}$ may limit the obtainable resolution 
(Grimm et al. 1998), we not only applied ECT but also a complimentary technique, using serial sections of highpressure frozen, freeze substituted, resin-embedded samples (e.g. van de Meene et al. 2006; Wickert et al. 2004). The sections validate the interpretation of an earlier study (Rachel et al. 2002) showing that the cytoplasmic membrane releases vesicles into the periplasm and also engulfs vesicles into the cytoplasm. In addition, the data give new insight into the cell biology of I. hospitalis and N. equitans: they prove the existence of cytoplasmic filaments, they show the different modes of cell division in I. hospitalis and $N$. equitans, and they give first insight into the complexity of the dedicated structures interconnecting the two archaeal cells.

\section{Materials and methods}

Archaeal strains and growth medium

The type strain I. hospitalis $\mathrm{KIN} 4 / \mathrm{I}^{\mathrm{T}}$ was obtained from the Culture Collection of the Institute for Microbiology and Archaea Centre, University of Regensburg. Cells were grown in $1 / 2 \mathrm{SME}$ medium at $90^{\circ} \mathrm{C}$, as described (Huber et al. 2000; Paper et al. 2007), with elemental sulphur as electron donor and a gas phase consisting of $\mathrm{H}_{2} / \mathrm{CO}_{2}$ $(250 \mathrm{kPa} ; 80 / 20, v / v)$.

\section{Sample preparation}

For optimal preservation of the ultrastructure, we used a technique described earlier (Rieger et al. 1995, 1997), based on a method described by Hohenberg et al. (1994), with minor modifications. Cell suspensions were taken up in cellulose capillaries, both ends sealed with glue, and transferred into $20 \mathrm{ml}$ of culture medium in serum bottles, which were pressurized with gas (see above). After incubation, the capillaries were inspected for cell growth by means of phase contrast light microscopy (Zeiss Axioplan, objective lenses: $40 \times$ NA $0.75 ; 100 \times$ Oil NA 1.3 ). Samples were cryo-immobilized by high-pressure freezing (Wohlwend Compact HPF 01; M. Wohlwend Engineering, Sennwald, Switzerland; Buser et al. 2007) and dehydrated by freeze-substitution $\left(8-15 \mathrm{~h}\right.$ at $-90^{\circ} \mathrm{C} ; 8 \mathrm{~h}$ at $-60^{\circ} \mathrm{C} ; 6 \mathrm{~h}$ at $-30^{\circ} \mathrm{C}$ ), in the following substitution solvents: (a) AOUH: acetone, $2 \% \mathrm{OsO}_{4}, 0.1 \%$ uranyl acetate, $9.3 \%$ $\mathrm{H}_{2} \mathrm{O}$; (b) EGFU: $94.6 \%$ ethanol, $0.5 \%$ glutaraldehyde, $1 \%$ formaldehyde, $0.5 \%$ uranyl acetate, $5.4 \% \mathrm{H}_{2} \mathrm{O}$ (Walther and Ziegler 2002). Samples were rinsed in pure acetone twice at $0^{\circ} \mathrm{C}$, and embedded in Epon at room temperature, which was hardened at $60^{\circ} \mathrm{C}$ for $48 \mathrm{~h}$. Single and serial ultrathin sections (thickness: about 50-70 nm) were obtained with a diamond knife (ultramicrotome: EM UC6,
Leica GmbH, Wetzlar, Germany). Sections were collected onto pioloform coated grids $(\mathrm{Cu}, 1 \times 2 \mathrm{~mm}$ slots or 200 mesh; Ni 200 mesh), and contrasted using 2\% uranyl acetate and lead citrate.

Immuno-labelling

Essentially, we followed a protocol recently established in our laboratory (Burghardt et al. 2007). Sections on grids were treated with $\mathrm{PBS}+0.1 \%$ glycine, to inactivate residual aldehyde on the section surface, then on PBS $+1 \%$ BSA to block unspecific binding ( 5 min each). Incubation with the primary antibody, diluted in PBS-BSA, was done for $45 \mathrm{~min}$. After five washing steps in PBS-BSA (2 min each), the sections were exposed to the secondary antibody (goat anti-rabbit $6 \mathrm{~nm}$ Gold, for $45 \mathrm{~min}$; or goat anti-rabbit ultrasmall gold, for $120 \mathrm{~min}$; both, 1:20 dilution in PBSBSA). After washing twice in PBS (2 min each), the antibodies were fixed with PBS $+1 \%$ glutaraldehyde $(5 \mathrm{~min}$ ). Sections were washed five times with $\mathrm{H}_{2} \mathrm{O}$ and contrasted as above. In case of secondary antibodies with ultrasmall gold particles, a silver enhancement was done as described (Danscher 1981; Stierhof et al. 1992).

Imaging

Grids were scanned for suitable specimen areas using a wide-angle video-rate CCD-camera (TV 673 Mk III; Gatan, Munich, Germany). Electron micrographs were recorded digitally using a slow-scan CCD camera $(1,024 \times$ 1,024 pixels; TVIPS GmbH, Gauting, Germany), at a primary magnification between 3,000 and $17,000 \times$ (absolute pixel size: $4.0-0.7 \mathrm{~nm}$ ). Because of the limited field of view of one image at these magnifications, up to 36 overlapping images were recorded of all cells in this study. A single montage was generated using the 'tiling software' (EM-MENU 3 or 4; TVIPS).

\section{$3 \mathrm{D}$ reconstruction}

Digital images were cut to identical square dimensions, scaled to 8 bit, reduced in resolution by binning, and read into AMIRA 4.0 (Visage Imaging, Fürth, Germany). Alignment of the images was done by translation and rotation. Contours of parts of the cells-the cytoplasmic and the outer membrane; the vesicles in the cytoplasm and periplasm-were outlined and colour-coded for each single image of a series. The final reconstruction included a smoothing of the surface, in order to reduce the rigid steps due to the individual sections in the resulting 3D models. For better visualization of details, movies of rotating cells (available as supplementary material) were recorded using a 'movie maker' integrated in the software package. 
Electron cryotomography

Suspensions of I. hospitalis and N. equitans cells were applied onto grids with holey carbon films, plunge-frozen in liquid ethane, and stored under liquid nitrogen. Electron cryotomography was performed on a FEI CM 300 FEG at $300 \mathrm{keV}$, equipped with a Gatan Imaging Filter GIF 2002 (Gatan, München, Germany). Tilt series were recorded in a tilt range from $-50^{\circ}$ to $+60^{\circ}$, with $2^{\circ}$ increment. After alignment using gold clusters as fiducial markers, the $3 \mathrm{D}$ reconstruction was obtained by weighted back-projection using IMOD (Mastronarde 1997) or the EM programme (Hegerl 1996). The final data set was median-filtered and visualized using AMIRA. Segmentation of the $N$. equitans and I. hospitalis cell walls was done manually; the filamentous connections were detected automatically using a computational correlation of filamentous structures perpendicular to the cell membranes (Linaroudis and Baumeister, unpublished).

\section{Results}

Light microscopy observations

Our experiments started with the inoculation of $200 \mu \mathrm{m}$ thick cellulose capillaries with about $1-2 \mu$ of a cell suspension of living I. hospitalis together with $N$. equitans. The capillaries were sealed with glue, rather than with hot forceps tips, as in a previous study (Rieger et al. 1995), and incubated in culture medium for about $28 \mathrm{~h}$. Growth of I. hospitalis cells inside the lumen of capillaries proceeded to significantly higher densities than when grown in liquid medium, as observed by phase contrast light microscopy (Fig. S1 in electronic supplementary material). Because only a $40 \times$ objective lens (NA 0.75 ) could be used, $N$. equitans cells were too small to be identified. In the surrounding medium, I. hospitalis cells with one to ten adherent $N$. equitans were regularly found, using a $100 \times$ objective lens. In semi-thin crosssections after resin (Epon) embedding (Fig. S1B), cells were predominantly seen in the close vicinity of the inner surface of the cellulose capillaries; hardly any cells were found in the inner part of the capillary lumen. When ultrathin sections of capillaries were observed by transmission electron microscopy (TEM), about five cells of I. hospitalis were found per section, most of them in the vicinity of the capillary, in a distance of up to $\sim 10 \mu \mathrm{m}$. On average, only one-twentieth to one-tenth of the I. hospitalis cells was sectioned in a plane which contained at least one $N$. equitans cell. This shows that the number of suitable sections is limiting in such an approach.
Ultrastructure of a whole cell of Ignicoccus hospitalis

A 2D projection of a plunge-frozen whole cell of I. hospitalis in a near-native state, imaged in a 300-keV FEG-TEM, is shown in Fig. S2A in electronic supplementary material. Two 'flagella'-like appendages emanate from the cell surface (Fig. S2A; white arrows and arrowheads). The two appendages are anchored in (or underneath) the cytoplasmic membrane, and traverse the periplasmic space. This is barely visible in the reproduction for the figure, because of very low contrast. In ultrathin sections, this has not been observed, yet. Figure S2B shows the XY slice of a tomogram (3D reconstruction) of a tilt series of another I. hospitalis cell: the cytoplasmic membrane, enclosing the tightly packed cytoplasm; the 100-nm wide, less crowded periplasmic space, and the outer membrane. Although the large diameter of the cell $(2-3 \mu \mathrm{m})$ limits the resolution of the tomogram, ribosome-like particles and regions of 'dense aggregates' can be seen.

The cytoplasm of I. hospitalis and cell division

Cells of I. hospitalis, when prepared by high-pressure freezing and freeze substitution, exhibited a tightly packed, almost homogenous, fine granular cytoplasm (Figs. 3, 4, 5, $6,7)$. It is densely contrasted, in particular in direct comparison with the periplasm or the resin surrounding the cells, both of which show no contrast. In about one-third of all sections of intact I. hospitalis cells, longitudinal fibres were observed in the cytoplasm, up to $500 \mathrm{~nm}$ in length, and 30$100 \mathrm{~nm}$, rarely up to $300 \mathrm{~nm}$ wide, which in most cases were straight, rarely slightly bent (Fig. 1). Their distribution in the cytoplasm varied: they were not preferentially localized in the centre of the cell or close to the membrane. When cells were freeze-substituted in EGFU (Fig. 1b), the fibres exhibited a fine texture, like a regular arrangement of subunits in bundles of thin filaments. The main periodicities on the longitudinal axis were at $(15 \mathrm{~nm})^{-1}$ and $(7.5 \mathrm{~nm})^{-1}$, and on the transverse axis at $(20 \mathrm{~nm})^{-1},(10 \mathrm{~nm})^{-1}$, and, rarely, at $(6.6 \mathrm{~nm})^{-1}$. Obviously, the molecular structure of the fibres was better preserved after freeze-substitution in EGFU than in AOUH. Their presence did neither depend on the size of the I. hospitalis cells nor the presence of $N$. equitans cells.

Very rarely, cells of $I$. hospitalis were visualized in the course of cell division (Fig. 2). In a first step, the cytoplasm divided into two parts. The separation did not proceed, as known for many prokaryotes and as observed for $N$. equitans (Figs. 6a, 7g, h), by constriction from the outside, but by some kind of invagination, propagating in a broad front or from many distinct spots, possibly in a direction perpendicular to the section plane. The dividing plane between the two cytoplasms, when seen at high magnification (Fig. 2d), 


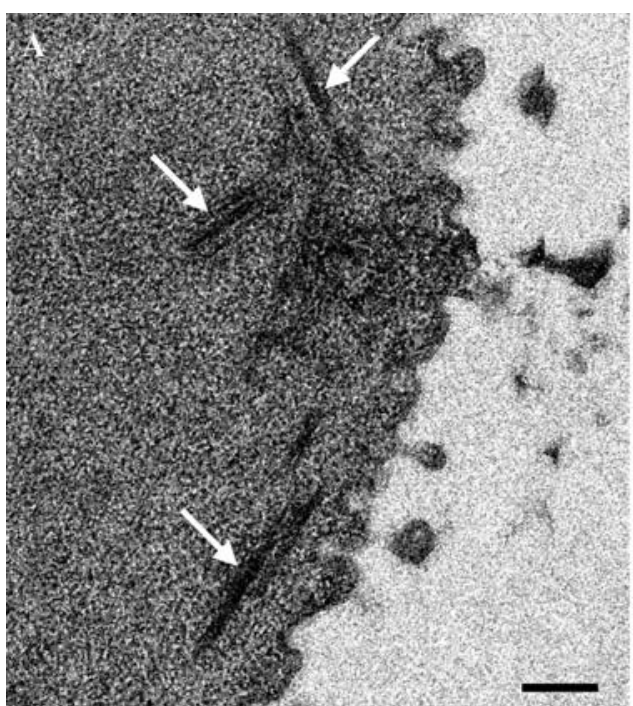

Fig. 1 Filaments in the cytoplasm of I. hospitalis cells, observed in transmission electron micrographs of ultrathin sections. Following cultivation in cellulose capillaries, cells were cryo-immobilized, freezesubstituted, and embedded in Epon. For a cells were freeze-substituted in AOUH; for $\mathbf{b}$ in EGFU. a Cytoplasmic filaments are marked by

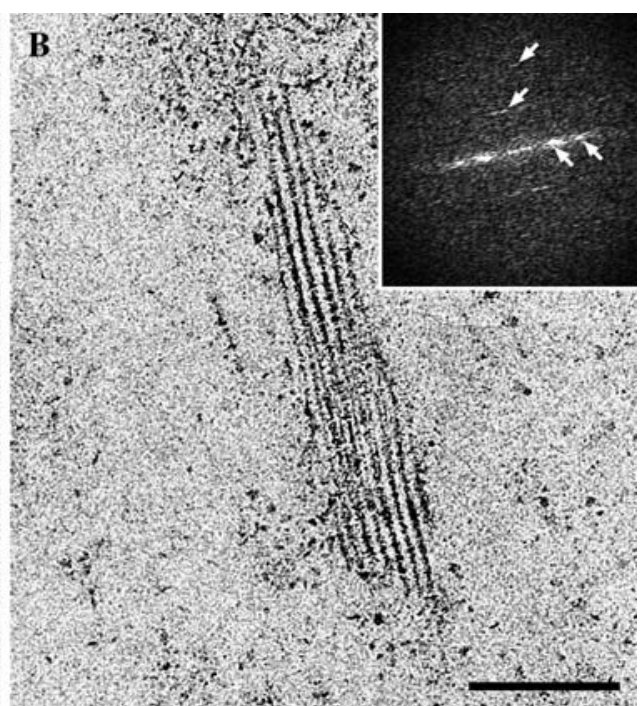

white arrows. b Cytoplasmic filaments composed of protofilaments, with regular arrangement of subunits. Inset in $\mathbf{d}$ Fourier spectrum of the longitudinal fibre. White arrows point to periodicities at $(15 \mathrm{~nm})^{-1}$ and $(7.5 \mathrm{~nm})^{-1}$ on the longitudinal axis, and at $(20 \mathrm{~nm})^{-1}$ and $(10 \mathrm{~nm})^{-1}$ on the transverse axis. Bars $200 \mathrm{~nm}$
Fig. 2 Stages of cell division in I. hospitalis, observed in transmission electron micrographs of ultrathin sections. In all three cells, the two cytoplasms are almost or fully separated, but yet included in one outer membrane. a Cell in the early stage of division; the gap between the two cytoplasms is shown enlarged in $\mathbf{d}$. $\mathbf{b}$ and $\mathbf{c}$ Cells in a later stage of division. Boxed area in $\mathbf{b}$ is shown enlarged in Fig. 3e. Cells were prepared as described in "Materials and methods", with freeze-substitution in AOUH. Bars $1 \mu \mathrm{m}(\mathbf{a}-\mathbf{c}), 200 \mathrm{~nm}(\mathbf{d})$
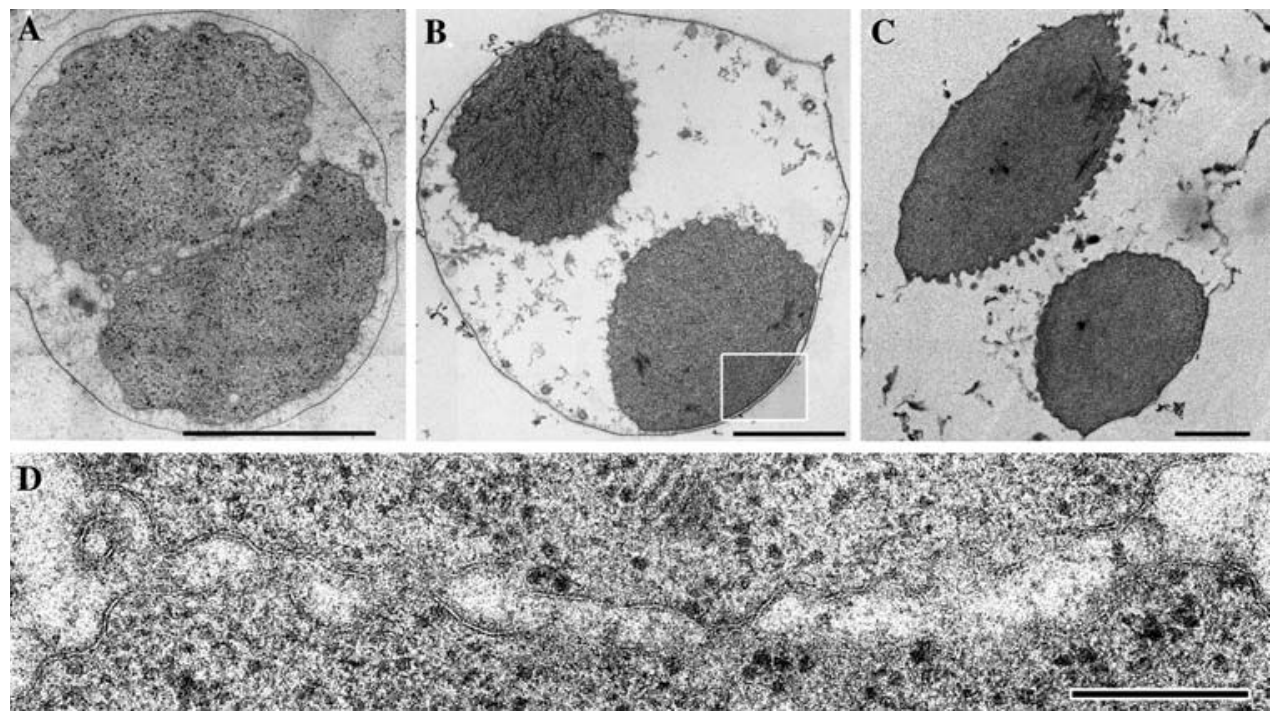

appears irregular: at some spots, a gap has formed, which is delineated by two cytoplasmic membranes, enclosing a space with low density, like in the periplasm. At other spots, the two cytoplasms are not separated, yet. In a next step, the two cytoplasms separate and round up (Fig. 2b). Later, numerous vesicles are released from the cytoplasmic membrane into the periplasm between both cytoplasms (Fig. 2c). This process ultimately leads to the formation of a new outer membrane in a plane between the two cytoplasms (Fig. 6 in Rachel et al. 2002).

In very few cells, the cytoplasm exhibited lower contrast, i.e. it was less densely packed, and concomitantly, the periplasm almost had the same contrast as the cytoplasm
(Fig. 4). Serial sections revealed that the cytoplasmic membrane was damaged in several slices, i.e. at one spot, which resulted in an 'outflow' of cytoplasmic material into the periplasm (Fig. 4b).

\section{The I. hospitalis outer membrane}

Each cell of I. hospitalis contains two membranes, the cytoplasmic membrane, the boundary of the cytoplasm, and the outer membrane, which delineates the periplasm outside the cell. Figure 3 shows the outer membrane of one cell (Fig. 3c) in different manifestations: in most cases as an asymmetric double line, i.e. a strongly contrasted, outer 
Fig. 3 Outer membrane structure in I. hospitalis, observed in transmission electron micrographs of ultrathin sections, prepared as described in "Material and methods"; freeze-substitution was in AOUH. Three parts of the cell shown in $\mathbf{c}$ are enlarged in $\mathbf{a}, \mathbf{b}$, and $\mathbf{d}$; the arrows point to the outer membrane, shown as asymmetric membrane (a), as symmetric membrane (b), and as split membrane (d). Outer membrane and cytoplasmic membrane in close and constant vicinity (Fig. 2b) are shown enlarged in e. Outer and cytoplasmic membrane are shown almost fused in $\mathbf{f}$. $C y$ cytoplasm, $C M$ cytoplasmic membrane, $P p$ periplasm, $O M$ outer membrane. Bars $1 \mu \mathrm{m}(\mathbf{c}), 200 \mathrm{~nm}(\mathbf{a}, \mathbf{b}$, d-f)
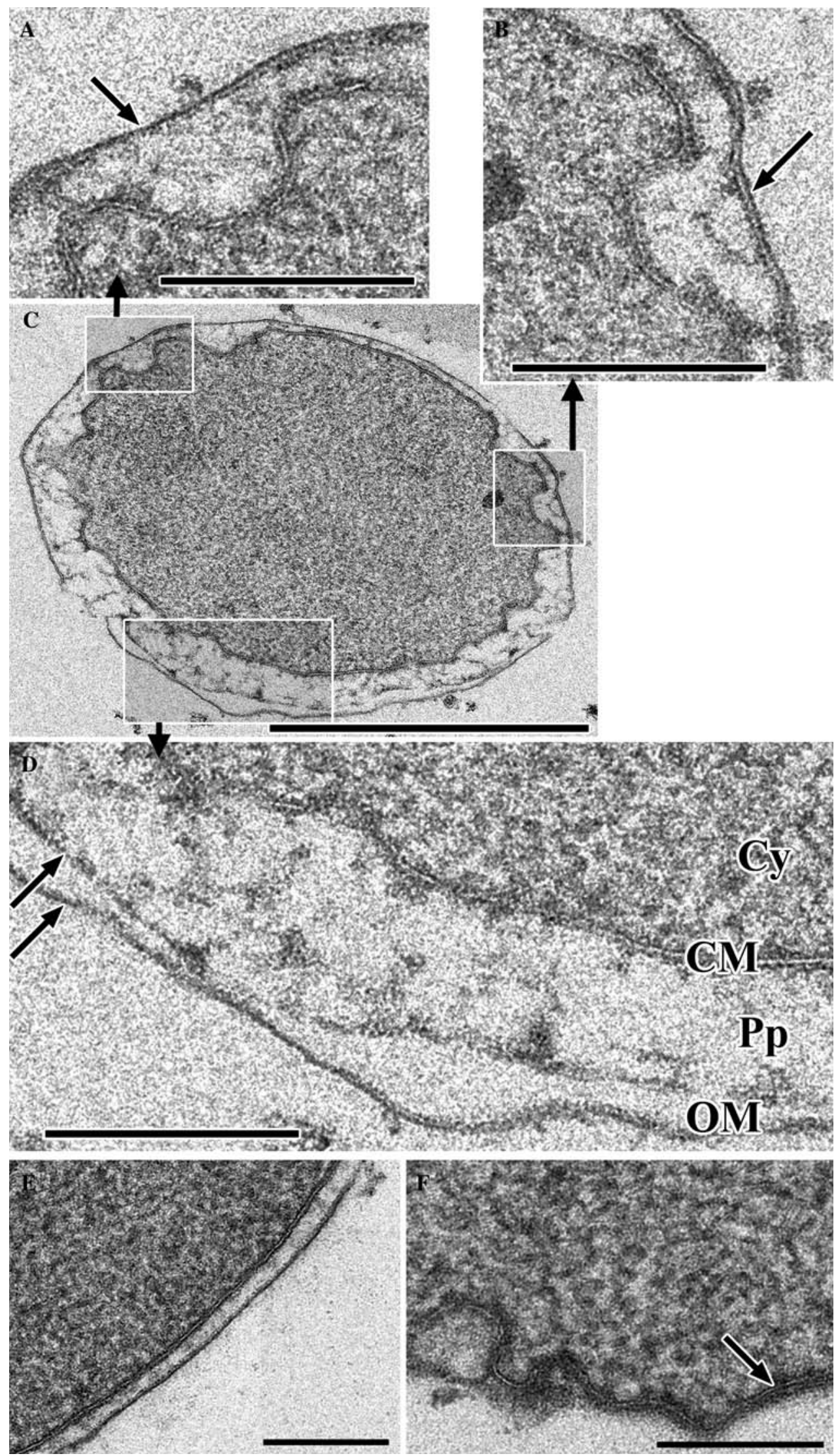
line, accompanied by a weakly contrasted, inner line (Fig. 3a); occasionally as two apparently identical, parallel lines, i.e. with same contrast (Fig. 3b). Rarely, the outer membrane is seen as two separate lines, i.e. it is split into two single leaflets, which are not identical in contrast (Fig. 3d). The thickness of the double lines is at about 8$10 \mathrm{~nm}$, the single lines at $4 \mathrm{~nm}$. The cytoplasmic membrane is easily identified as two parallel lines with same contrast (Fig. 3a, b, d), i.e. as a symmetric membrane with a thickness of about $10 \mathrm{~nm}$.

The distance between the outer membrane and the cytoplasmic membrane varies considerably, as illustrated in Figs. 2, 3, 4, 5 and 7. In most cells, cytoplasmic membrane and outer membrane are not in close vicinity with each other in about $80-90 \%$ of the circumference of the cell. They are separated from each other by a distance of 30 $500 \mathrm{~nm}$, rarely up to $1 \mu \mathrm{m}$ (Fig. $7 \mathrm{~g}$ ), thus defining the large periplasmic space. In the remainder of the circumference of the cell, however, the two membranes are either in close and almost constant vicinity-about $20-30 \mathrm{~nm}$ in width (Fig. 3e)—or in direct contact with each other (Fig. 3f). The size of the contact area is difficult to determine quantitatively if only single sections are available; it is estimated to about $10-20 \%$ of the area of the cytoplasmic membrane, using geometrical considerations on a spherical segment of the cell shown in Fig. 5.

\section{D reconstruction of $I$. hospitalis from serial sections}

As shown above (Fig. S2), the large diameter of an I. hospitalis cell is not favourable for electron cryotomography of whole cells. Therefore, we used serial sections in order to obtain a 3D reconstruction. Considering the diameter of a single cell with about $2 \mu \mathrm{m}$, this cell would be completely visualized in a minimum of about 30 sections, $70 \mathrm{~nm}$ each.
We were able to complete two series, both with more than 20 sections, in both cases covering more than half of an $I$. hospitalis cell (Figs. 4, 5). The result of the first series comprising 28 sections (Fig. 4) shows about half a cell with a rather smooth cytoplasmic membrane, with only few vesicles in the periplasm. In addition, the two compartments, the cytoplasm and the periplasm, differ only slightly in the staining intensity. A closer look reveals that the cytoplasmic membrane of this particular cell is opened, i.e. damaged (Fig. 4b), and the contents of the cytoplasm are released into the periplasm. Possibly, this is not the result of the sample preparation process, as another cell in the same section exhibited a densely contrasted cytoplasm, i.e. the cytoplasmic membrane was intact (not shown). Nevertheless, the 3D representation of this cell (volume: $\sim 7.2 \mu \mathrm{m}^{3}$; Fig. 4e) gives a good impression of the huge volume of the periplasm $\left(\sim 4.8 \mu \mathrm{m}^{3}\right)$, in comparison to the volume of the cytoplasm $\left(\sim 2.4 \mu \mathrm{m}^{3}\right)$.

The second series comprised 23 sections in total (Fig. 5). In the 3D reconstruction (Fig. 5e, f), the outer membrane was artificially removed, in order to reveal a clear view onto the cytoplasmic membrane (orange), in particular its high degree of undulation and the vesicles that were formed in the periplasm. Some vesicles had no contact with the cytoplasmic membrane, as clarified in the 3D visualization. This is best visualized in movies showing the cell in rotation (supplementary material). A small part of the cytoplasmic membrane was, as in other cells, in close vicinity, or in contact with the outer membrane; this area is highlighted in yellow. On the outer membrane of this I. hospitalis cell, a cell of $N$. equitans was found to be attached (Fig. 5a). The contact site was, unfortunately, sectioned in an oblique angle, thereby obscuring any detail (not shown). In this cell, the volume of the periplasm was about $3 \mu \mathrm{m}^{3}$, and that of the cytoplasm about $4.4 \mu \mathrm{m}^{3}$.
Fig. 4 3D reconstruction of half a cell of $I$. hospitalis on the basis of 28 serial ultrathin sections. Sample was prepared as described in "Materials and methods". a-d Four selected equidistant sections of the whole data set. e 3D reconstruction of the data set, generated in AMIRA $^{\circledR}$, based on all ultrathin sections. Volumes of the cytoplasm and the periplasm are given in the text. White arrows point to periplasmic vesicles. Purple/rose cytoplasmic membrane. Pale yellow outer membrane. Bars $1 \mu \mathrm{m}$
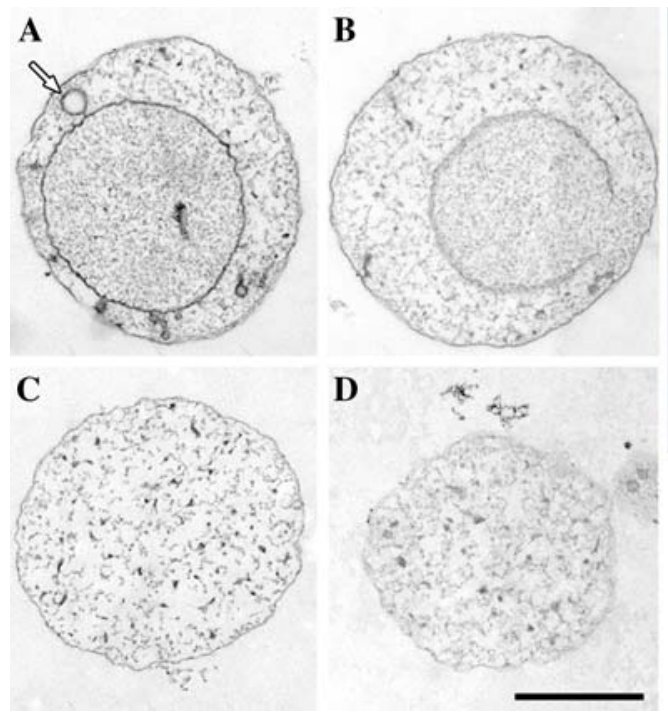

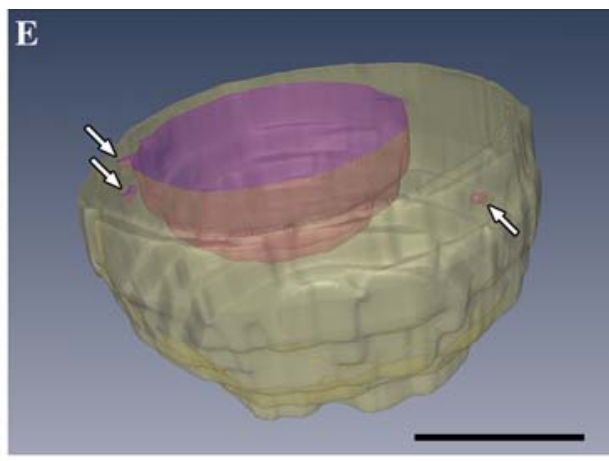



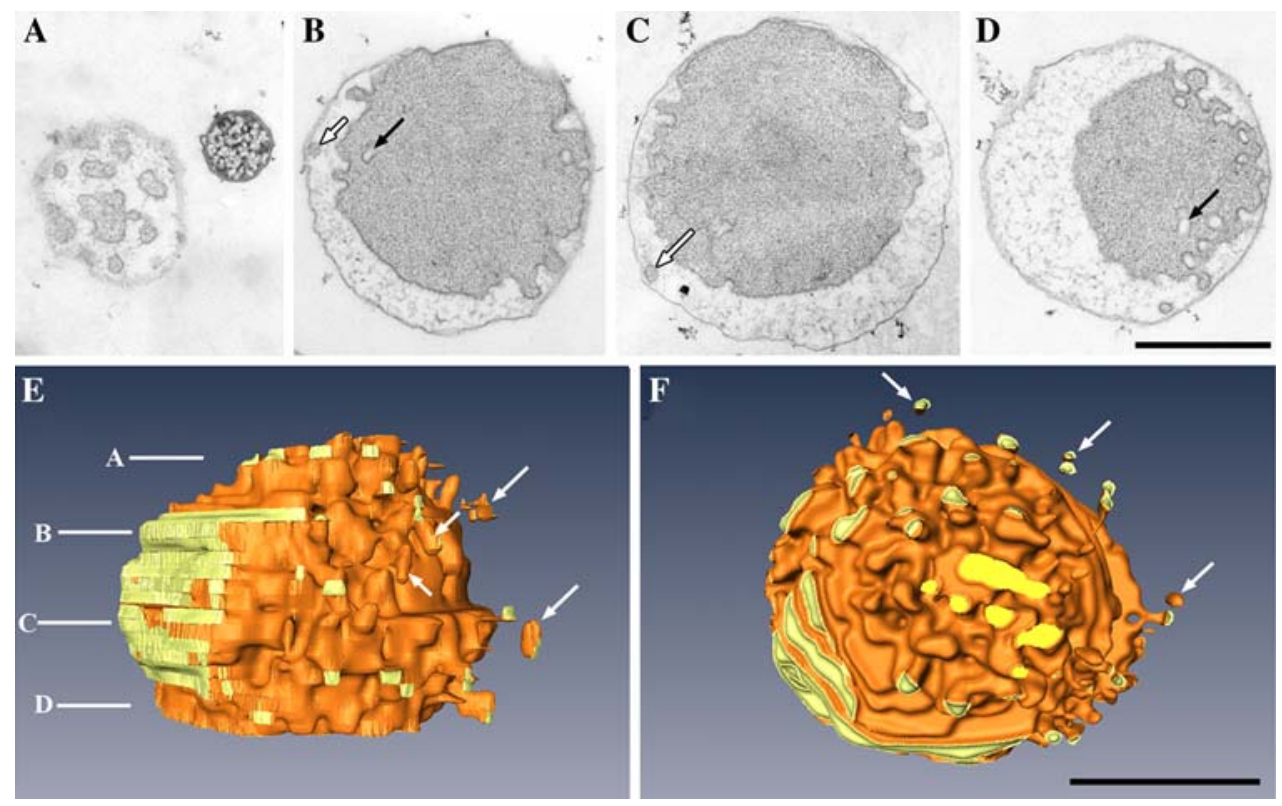

Fig. 5 3D reconstruction of two-third of a cell of $I$. hospitalis on the basis of 23 serial ultrathin sections. Sample was prepared as described in "Materials and methods". a-d Four selected sections of the whole data set. e, $\mathbf{f} 3 \mathrm{D}$ reconstruction, generated in AMIRA after stripping away the outer membrane, in order to visualize the periplasmic vesicles and the cytoplasmic membrane. e Side view; f top view. Orange surface area of the cytoplasmic membrane forming/releasing vesicles;

\section{Ultrastructure of N. equitans cells}

In ultrathin sections, cells of $N$. equitans appear as round, occasionally lobed cocci (Figs. 6, 7, 8). They exhibit a tightly packed, densely stained cytoplasm, which is surrounded by a cytoplasmic membrane, a 20 -nm wide periplasmic space, and as outermost sheath, an S-layer, a twodimensional array with imperfect crystallinity, made up of multiple copies of a single glycoprotein (Schuster, Huber and Rachel, unpublished). Depending on the substitution medium, subtle differences are observed: after freeze-substitution in $\mathrm{AUOH}$, the cytoplasm is tightly packed and densely contrasted (Figs. 6a, 7a). After substitution in EGFU, the $N$. equitans cytoplasm exhibits a subtly differentiated fine structure: a central area is tightly packed and smooth, like the nucleoid observed in sections of other prokaryotes, while the periphery of the cytoplasm, close to the membrane, contains small spherical bodies, most likely ribosomes (Fig. 6b). In both cases, the periplasm is also stained, i.e. it is a compartment of the cell which contains (bio-)molecules (Figs. 6b, c, 7a, h). Rarely, N. equitans cells are elongated and/or show a central constriction, which most likely is an early phase of cell division (Figs. 6a, 7g). The data observed in ultrathin sections of freeze-substituted, resin-embedded cells are in good agreement with $\mathrm{XY}$ slices taken from tomograms of frozenhydrated cells, obtained by ECT: a central nucleoid and

yellow surface area of the smooth part of the cytoplasmic membrane, which is in close vicinity with the outer membrane. Horizontal white lines in the model in $\mathbf{e}$ indicate the approximate level of the sections shown in $\mathbf{a}-\mathbf{d}$, respectively. White arrows (in $\mathbf{b}, \mathbf{c}, \mathbf{e}, \mathbf{f})$ point to periplasmic vesicles; black arrows (in $\mathbf{b}, \mathbf{d}$ ) point to membrane vesicles in the cytoplasm. Bars $1 \mu \mathrm{m}$

ribosomes in the periphery of the cytoplasm are characteristic features (Fig. 6d). In addition, XY slices of the tomogram provide evidence that the cytoplasm of $N$. equitans contains elongated (Fig. 6d) and ring-shaped bundles of filaments (Fig. 6e), possibly elements of a kind of cytoskeleton; their biochemical nature is unknown, at present.

\section{Contact site between I. hospitalis and N. equitans}

Cell contact sites between the two Archaea in ultrathin sections are observed only rarely, because of the small area of this structural feature. In the course of this study, we were able to collect micrographs of about 120 contact sites, in total. For only $\sim 30$ of these, sample preservation, section plane and image quality were satisfactory in order to deduce structural information. Representative examples are shown in Fig. 7. From our recent experience with series of thin sections, each with a thickness of about $70 \mathrm{~nm}$, the contact is visualized at its best in one single section, only. Adjacent sections already show the two cells as being 'separated' from each other (Fig. 7f), i.e. no direct contact is visible.

The electron micrographs of cell contact sites were analysed especially for two aspects: the organization of the two I. hospitalis membranes, in particular the gap in between, and the gap between the two cell surfaces. First, the two membranes: In 25 of 30 micrographs $(83 \%), N$. equitans 
Fig. 6 Ultrastructure of N. equitans, incl. cell division, as seen by transmission electron microscopy of sections $(\mathbf{a}-\mathbf{c})$ and by electron cryotomography $(\mathbf{d}, \mathbf{e})$. For a-c cells were prepared for sections as described in "Materials and methods"; for a cells were freeze-substituted in AOUH; for $\mathbf{b}$ and $\mathbf{c}$ in EGFU. $S L$ S-layer, $P p$ periplasmic space, $C M$ cytoplasmic membrane. d, e XY slices from a tomogram of an N. equitans cell, obtained by ECT. White arrows point to longitudinal cytoplasmic filaments (d) and to ring-shaped filaments (e). Bars in $\mathbf{a}, \mathbf{b}, \mathbf{d}, \mathbf{e} 200 \mathrm{~nm}$. $\mathbf{c}$ Is part of $\mathbf{b}$, and further enlarged by a factor of two
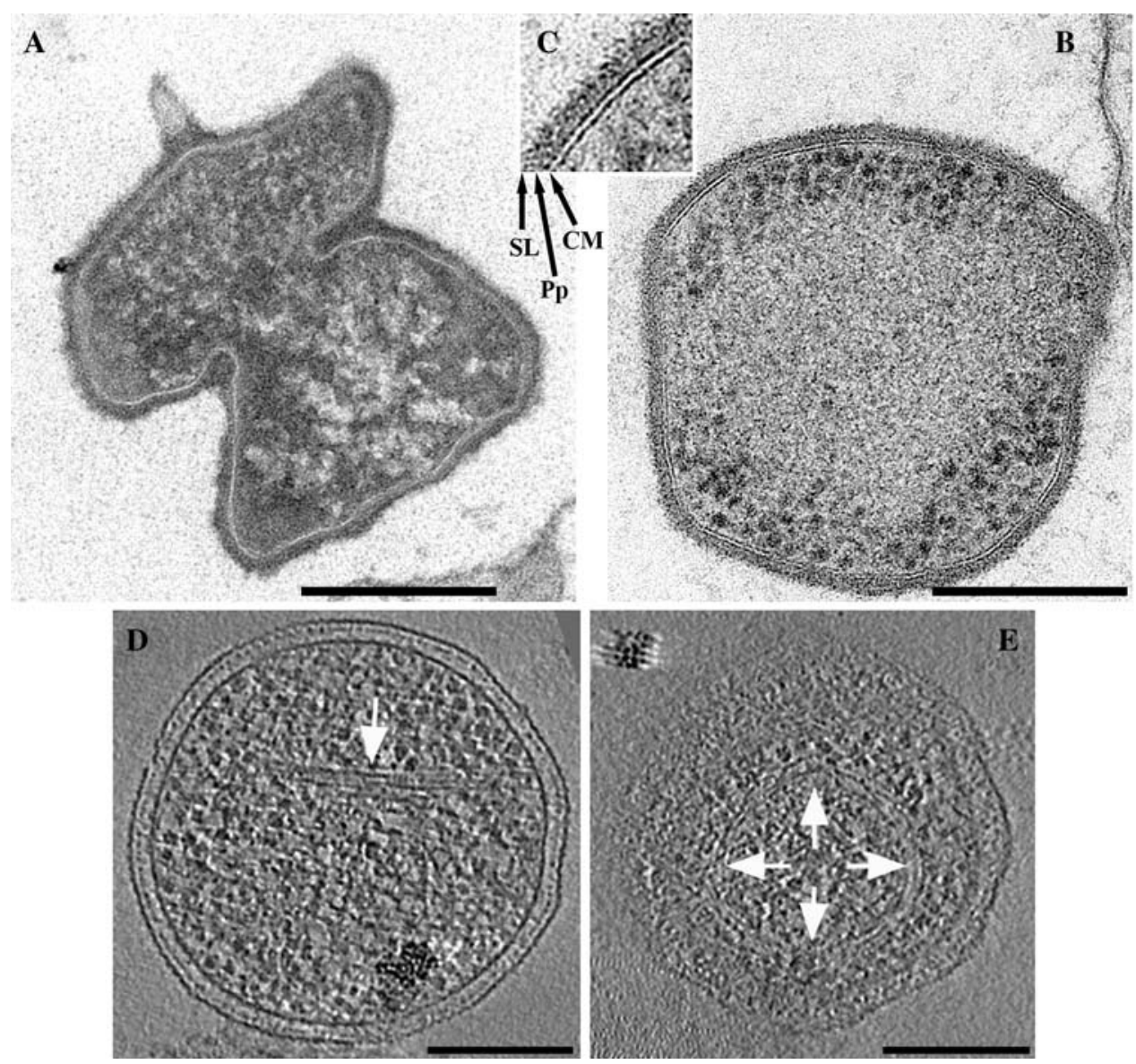

cells were found attached to I. hospitalis at a site where the cytoplasm of $I$. hospitalis and therefore also the cytoplasmic membrane were in direct contact with the outer membrane (Fig. 7b, d-f), or in close proximity; the gap had a maximum width of $30 \mathrm{~nm}$ (Fig. 7a, c) and did not contain periplasmic vesicles (which were only found in the remainder of the periplasmic space). At least in these cells, the cytoplasm appeared to play a role in the contact site, but not the periplasmic vesicles. In 5 of 30 of the micrographs (17\%), N. equitans cells were shown to be attached to the outer membrane of I. hospitalis where the I. hospitalis cell had an at least $300 \mathrm{~nm}$ wide periplasmic space, filled with numerous vesicles (Fig. 7g, h). At higher magnification (Fig. 7h), the outer membrane was seen to arch inwards towards a periplasmic vesicle, which was filled with densely stained material; the outer membrane and the vesicle membrane were in direct contact. In this cell, the periplasmic vesicles appeared to play a role in the contact site, while the cytoplasm was unlikely to be involved. Second, the gap between the cells: In at least $50 \%$ of the sites of cell contact, the gap between the two cell surfaces was about $50-60 \mathrm{~nm}$ wide, and contained a kind of fibrous material (Fig. 7a, d, e, g, h). In other sections, there was no gap between the two cell surfaces, i.e. the outer membrane of I. hospitalis and the S-layer of $N$. equitans were in direct contact (Fig. 7b, c). Hollow tubes were never observed between the cells.

These findings were supported and amended from tomographic data, obtained by ECT (Fig. 8), although in a more differentiated way. In one XY slice (Fig. 8a), the N. equitans cell was seen almost in direct contact with the I. hospitalis host. In another slice of the same tomogram (Fig. 8b), there was a gap of about $50 \mathrm{~nm}$ between both cell surfaces, and several thin fibres interconnected the two cells. Two of these fibres are visualized at higher magnification in Fig. 8c and $\mathrm{d}$. The extent of these connections was investigated by a computational search of the dataset using a correlation function, perpendicular to the cell membranes. The segmentation of the search result is shown in Fig. 8e. The filaments (yellow) connect the cytoplasm of $N$. equitans through its cell wall (blue) and reach through the membranes of I. hospitalis (purple) to the cytoplasm of the host cell.

From the data obtained so far, we can give a rough estimation of the area for the contact site. The surface of the $N$. equitans cell is in the range of $500,000 \mathrm{~nm}^{2}$. For a contact site with a diameter of $40 \mathrm{~nm}$ (Fig. 7b), the contact area is at around $1,250 \mathrm{~nm}^{2}$, i.e. $1 / 400$ of the $N$. equitans surface. If the contact site is as large as $170 \mathrm{~nm}$ (Fig. 8a), it is at $22,000 \mathrm{~nm}^{2}$ and therefore $1 / 22$ of the $N$. equitans surface. 

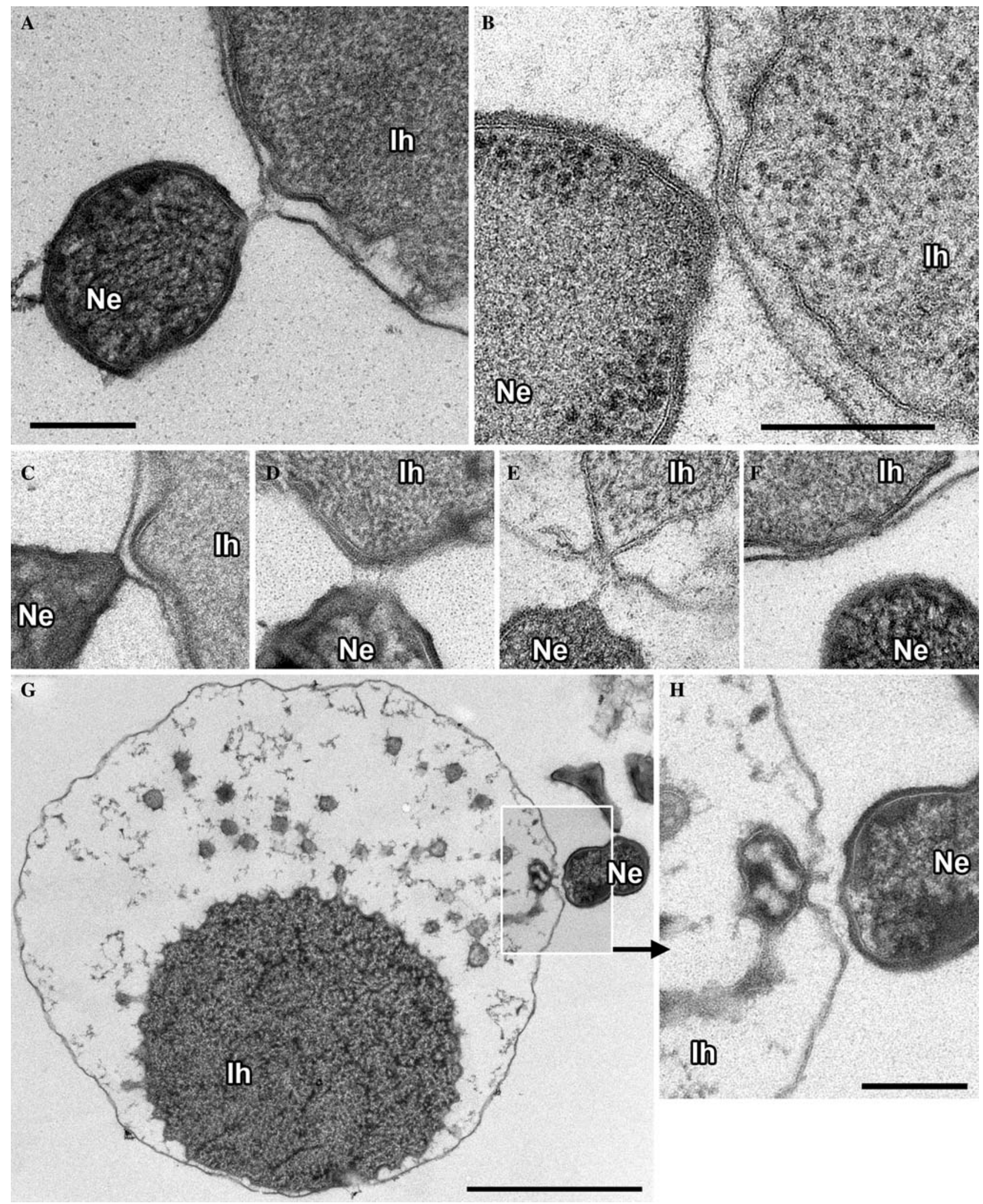

\section{Discussion}

For the electron microscopy investigation of this study, cells of I. hospitalis in co-culture with $N$. equitans were grown inside the lumen of cellulose capillaries. In this container, cells grow to considerably higher density than planctonic in liquid medium (Rieger et al. 1995, 1997; Paper et al. 2007), and any centrifugation step is avoided 
4 Fig. 7 Contact sites of I. hospitalis with cells of N. equitans in transmission electron micrographs of ultrathin sections. Samples were prepared as described in "Materials and methods", and freeze-substituted in AOUH (a, c-h) and in EGFU (b). a I. hospitalis (Ih) and N. equitans $(\mathrm{Ne})$ connected by fibrous material. b Outer membrane of I. hospitalis and the cell surface of $N$. equitans in direct contact, and, in addition, both membranes of I. hospitalis in close contact. c-f Four examples of the variation of contact sites; c direct contact of the I. hospitalis outer membrane with the cell surface of $N$. equitans. d, e Fibrous material in the gap between the two cells. $f$ In this section plane, the contact between the two cells is not visible; the two I. hospitalis membranes are in direct contact. $\mathbf{g}$ A different type of contact site between I. hospitalis ( $\mathrm{Ih}$ ) and $\mathrm{N}$. equitans $(\mathrm{Ne})$, interconnected by fibrous material. Here, the periplasmic space in I. hospitalis is large and contains vesicles. Note the elongation and central indentation of the $N$. equitans cell, indicating an early phase of division. Bars $1 \mu \mathrm{m}(\mathbf{g})$ and $200 \mathrm{~nm}$ (a, also for $\mathbf{c}-\mathbf{f}, \mathbf{b}, \mathbf{h}$ )

which might destroy the delicate cell-cell interaction between cells (Rieger et al. 1997). In addition, cellulose capillaries are ideal specimens in size and geometry for cryo-immobilisation using high-pressure freezing, freezesubstitution and resin embedding (Hohenberg et al. 1994). Although the cells grow to high densities inside the capillaries, still 'only' five, rarely also ten cells are observed in one 70-nm ultrathin section. These cells did not, however, suffer from centrifugation forces, and their ultrastructure was well preserved. In particular, the cytoplasm is tightly packed and densely contrasted, an aspect which is rarely seen in archaeal cells after conventional processing including chemical fixation and room temperature dehydration.

This method is, at present, the best way to obtain reliable and reproducible TEM results. Quite clearly, cryo-immobilisation is an absolute requirement in order to arrest these delicate archaeal cells in the living state (see also Rachel et al. 2002). Members of the genus Ignicoccus are-besides Thermoplasma - the only Archaea without any cell wall polymer which could reinforce and/or protect the cell envelope, like 2D crystalline S-layer sheets, or pseudomurein (König et al. 2007). During further processing of the samples, the use of EGFU for freeze-substitution turned out to be superior to AOUH; it helped to better preserve the fine structure of cytoplasmic filaments (in I. hospitalis cells), the compartmentalization in $N$. equitans cytoplasm (nucleoid in centre; ribosomes in the periphery), and the antigenicity in both cells. Samples prepared in this way were used in a recent study to show that one membrane protein, 'Ihomp1', was exclusively localized in the outer membrane of I. hospitalis cells (Burghardt et al. 2007, 2008). More recently, antibodies specifically raised against the S-layer protein of N. equitans were found to exclusively bind to the surface of these cells (K. Schuster, S. Gürster, C. Meyer, H. Huber, and R. Rachel, unpublished).

The possible function of the cytoplasmic filaments observed remains unclear, as long as they have not been isolated and characterized biochemically, and/or deletion mutants are available. Several explanations are possible: they might be intracellular (filamentous) crystals of cytoplasmic proteins naturally expressed in high amounts, like ribosome, thermosome, or peroxiredoxin (Burghardt et al. 2007, 2008). Crystals of similar size were also observed in sections of cells from another Crenarchaeum, Pyrodictium abyssi, prepared under identical conditions (Rieger et al. 1995). Alternatively, these crystals may also represent an (oblique) section through a bundle of an archaeal cytoskeleton, similar as observed in whole bacterial cells by electron cryotomography, e.g. in Caulobacter crescentus (Briegel et al. 2006), Magnetospirillum gryphiswaldense (Scheffel et al. 2006), and Spiroplasma melliferum (Kürner et al. 2005). Some of the bacterial cytoplasmic filaments are discussed to consist of MreB, an actin-like protein, or FtsZ, a protein with a tubulin fold (Löwe et al. 2004). At present, the biochemical nature of these filaments in I. hospitalis is unknown: in the annotated genome of I. hospitalis (see, e.g. http://imgweb.jgi-psf.org/cgi-bin/w/main.cgi), like for other Crenarchaeota, there is no hint for the presence of any of the mentioned genes.

Fibres were, in addition, observed in the $N$. equitans cytoplasm by ECT. One type was straight, i.e. similar to the
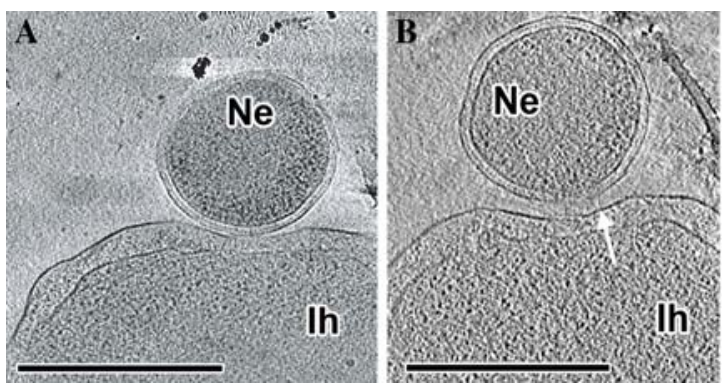

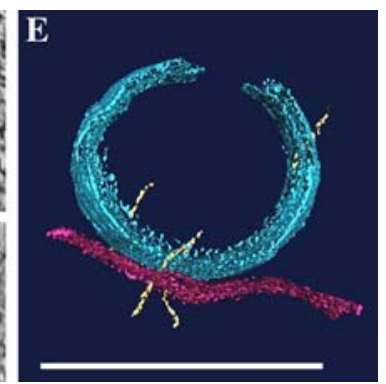

parts of $\mathbf{b}$. White arrows in $\mathbf{b}, \mathbf{c}$ and $\mathbf{d}$ point to fibres between the cells e Visualization of both cells after segmentation, using AMIRA. Red surface of the I. hospitalis cell; blue outer rim of the N. equitans cell; yellow fibres interconnecting both cells. Bars $500 \mathrm{~nm}$ 
filaments observed in other Bacteria and in I. hospitalis. The circular filaments were reminiscent of the ring-like structures observed for ftsZ-GFP by fluorescence light microscopy (Ma et al. 1996); the constriction of $N$. equitans cells might indicate the presence of an FtsZ ring in the division plane (Wang and Lutkenhaus 1993; Li et al. 2007). As a matter of fact, two genes were annotated to code for FtsZlike proteins in the genome of $N$. equitans (Waters et al. 2003). Electron micrographs showing stages of cell division are rare, most likely, because it is, in comparison to the doubling time, a fast process. For two other members of the Crenarchaeota, Pyrodictium abyssi and Thermoproteus tenax, cell division was shown to last only a few minutes, under in vivo conditions (Horn et al. 1999). The ultrastructural data clearly demonstrate that two very different modes of cell division exist in $N$. equitans and I. hospitalis: in $N$. equitans, by constriction in mid-plane of the cocci, and in $I$. hospitalis, by some kind of irregular invagination, separation of the two cytoplasms, and synthesis of a new outer membrane in the periplasm, between the cytoplasms. It will be interesting to analyse which proteins are involved in cell division, in particular in I. hospitalis. As cell division consumes energy and involves the reorganization of membranes, the search will also focus on yet unknown ATPases or GTPases, either integrated in or associated with the cytoplasmic membrane.

The Ignicoccus outer membrane is still unique among the Archaea (König et al. 2007). It contains, in contrast to the cytoplasmic membrane, diether lipids only, but no tetraether lipids (Jahn et al. 2004), and therefore, the two leaflets can fracture in freeze-etch experiments (Rachel et al. 2002) and, artificially, during freeze-substitution and embedding (Fig. 3d). It also has a very limited protein inventory, i.e. million copies of a single and small protein, 'Ihomp1', in form of pore-forming complexes (Burghardt et al. 2007). These data and the lipid analyses (Jahn et al. 2004) suggest the presence of mechanisms to sort and process those lipids and proteins which are destined for the outer membrane: either at the cytoplasmic membrane, at the contact site of cytoplasmic and outer membrane, or in the periplasmic vesicles. The micrographs of dividing I. hospitalis cells (Fig. 2) let us assume that, during cell division, these vesicles are involved in the delivery of constituents of a new outer membrane, e.g. the (selective) transport of diether lipids and protein precursors out of the cytoplasmic membrane. Other micrographs (Fig. 7g, h) suggest that they also act as vehicles for the directed transport of metabolites through the periplasm to the outer membrane, where they are finally released to the 'symbiont' $N$. equitans. Currently, we are developing methods to obtain the vesicles in sufficient amounts for biochemical analyses, in order to clarify their content and possible function; so far, no conclusive results were obtained yet.
This study provided first insights into the structure of the contact sight between I. hospitalis and $N$. equitans. This is fundamental, in order to understand how the postulated transport of metabolites is organized at the subcellular level. There is no evidence for the presence of tubular structures, like in Pyrodictium (Nickell et al. 2003), or that the two cytoplasms fuse, in form of a cytoplasmic 'bridge'. Thin sections and ECT data show the existence of an area, where the surface structures of the two cells are either in close vicinity (with some fibres in the gap between the cells), or in direct contact. These two different modes of contact may represent different states, on the timescale, which we cannot resolve, at present. In cross-sections, the site of direct contact measures $40-50 \mathrm{~nm}$, resulting in an area of $\sim 1,000$ $2,000 \mathrm{~nm}^{2}$. (We assume that the area of the contact site in Fig. $8 \mathrm{e}$ is artificially enlarged due the fact that cells for ECT needed to be concentrated by a short centrifugation step.) The area is large enough to include at least $25-50$ of the 7$\mathrm{nm}$ outer membrane pores, made of the Ihomp1 protein (Burghardt et al. 2007), and, in the I. hospitalis and N. equitans cytoplasmic membranes, at least 50-100 ABC transporters, which might be involved in the contact site (Hollenstein et al. 2007). Transporters of this type are encoded by the genomes of both organisms. They are known to utilize the energy of ATP hydrolysis to carry a wide variety of substrates across membranes. Two 'binding proteins', components of $\mathrm{ABC}$ transporters, were recently shown to be expressed in I. hospitalis cells (Burghardt et al. 2008). This would be sufficient to transport small molecules like amino acids (and possibly also nucleotides) from I. hospitalis to $N$. equitans, as was recently demonstrated (Jahn et al. 2008). Even the necessary transport of lipids (Jahn et al. 2004) might be arranged by ABC transporters (Dean et al. 2001); this needs to be verified in the case of these Archaea. In the surrounding of the contact site, a corona of thin fibres was found which might help to stabilize the delicate contact site. These fibres seem to be in contact with or anchored in the cytoplasmic membranes of both organisms. In addition, we also provide evidence for an alternative transport of metabolites via periplasmic cargo vesicles, as it was previously suggested (Waters et al. 2003).

The limitation of the current 3D data is the low resolution in the third dimension: in the case of serial sections, this is due to the section thickness of $70 \mathrm{~nm}$. This may be reduced by a factor of two, if thinner sections are available, but there is doubt, whether the gain in information is worth the huge effort. Electron cryotomography of intact cells might be used, too, but is constrained in this special case by the huge diameter of $I$. hospitalis cells, often exceeding $2 \mu \mathrm{m}$, a fact which limits the resolution attainable in the reconstruction (Grimm et al. 1998). Other, yet unexplored routes for obtaining 3D information on this type of specimen are cryo-electron microscopy of vitrified sections 
(CEMOVIS; Al-Amoudi et al. 2004), or the use of a dual beam scanning electron microsope (FIB-SEM; Heymann et al. 2006); both are not accessible to us, at present, and the specimen preparation and imaging conditions would require careful testing.

For the continuation of our project, we aim to use sequential tomographic reconstructions of semi-thin serial sections, using single or dual-axis tomography (Mastronarde 1997; Nickell et al. 2003), following cryo-immobilization, freeze-substitution and embedding. This approach was successfully applied to cells of Schizosaccharomyces pombe (Höög et al. 2007). It is laborious but viable at least, and has another advantage: embedded and sectioned cells as described here are amenable to post-embedding immunolabelling using specific antibodies. This is, at present, an advantage over ECT, where labelling techniques have not been elaborated, yet. In addition, we are in the course of biochemically identifying and characterizing proteins which are important for maintaining the cell envelope of I. hospitalis and N. equitans, like membrane proteins and the S-layer, and to raise antibodies (Burghardt et al. 2007; Burghardt et al. 2008; D. Müller, C. Meyer, R. Wirth, H. Huber, R. Rachel, unpublished). Using serial sections in combination with tomography, we aim to shed further light on the unique and delicate interaction between these two Archaea.

Acknowledgments The authors thank Prof. Dr. Karl O. Stetter, Prof. Dr. Wolfgang Baumeister, Prof. Dr. Michael Thomm, Prof. Dr. Ralph Witzgall and Dr. Ulrike Jahn for continuous support and stimulating discussions and Peter Hummel for expert technical assistance. The work was supported by grants of the Deutsche Forschungsgemeinschaft to R. Rachel and H. Huber (Ra 751/5-1, HU 703/1-3, and SPP1112)

\section{References}

Al-Amoudi A, Chang J-J, Leforestier A, McDowall A, Salamin LM, Norlén LPO, Richter K, Sartori Blanc N, Studer D, Dubochet J (2004) Cryo-electron microscopy of vitreous sections. EMBO J 23:3583-3588

Briegel A, Prabha Dias D, Li Z, Jensen RB, Frangakis AS, Jensen GJ (2006) Multiple large filament bundles observed in Caulobacter crescentus by electron cryotomography. Mol Microbiol 62:5-14

Burghardt T, Näther DJ, Junglas B, Huber H, Rachel R (2007) The dominating outer membrane protein of the hyperthermophilic archaeum Ignicoccus hospitalis: a novel pore-forming complex. Mol Microbiol 63:166-176

Burghardt T, Saller M, Gürster S, Müller D, Meyer C, Jahn U, Hochmuth E, Deutzmann R, Siedler F, Babinger P, Wirth R, Huber H, Rachel R (2008) Insight into the proteome of the hyperthermophilic Crenarchaeon Ignicoccus hospitalis: the major cytosolic and membrane proteins. Arch Microbiol. doi:10.1007/s00203008-0399-x

Buser C, Walther P, Mertens T, Michel D (2007) Cytomegalovirus primary envelopment occurs at large infoldings of the inner nuclear membrane. J Virol 81:3042-3048
Danscher G (1981) Localisation of gold in biological tissue. A photochemical method for light- and electron microscopy. Histochemistry 71:81-88

Dean M, Hamon Y, Chimini G (2001) The human ATP-binding cassette (ABC) transporter superfamily. J Lipid Res 42:1007-1017

Frank J (1992) Electron tomography. Plenum Press, New York

Grimm R, Singh H, Rachel R, Typke D, Zillig W, Baumeister W (1998) Electron tomography of ice-embedded prokaryotic cells. Biophys J 74:1031-1042

Hegerl R (1996) The EM program package: a platform for image processing in biological electron microscopy. J Struct Biol 116:30 34

Heymann JAW, Mayles M, Gestmann I, Giannuzzi LA, Lich B, Subramaniam S (2006) Site-specific 3D imaging of cells and tissues with a dual beam microscope. J Struct Biol 155:63-73

Hohenberg H, Mannweiler K, Müller M (1994) High-pressure freezing of cell suspensions in cellulose capillaries. J Microsc 175:34-43

Höög JL, Schwartz C, Noon AT, O’Toole ET, Mastronarde DN, McIntosh JR, Antony C (2007) Organization of interphase microtubules in fission yeast analyzed by electron tomography. Dev Cell 12:349-361

Hollenstein K, Frei DC, Locher KP (2007) Structure of an ABC transporter in complex with its binding protein. Nature 446:213-216

Horn C, Paulmann B, Kerlen G, Junker N, Huber H (1999) In vivo observation of cell division of anaerobic hyperthermophiles by using a high-intensity dark-field microscope. J Bacteriol 181:5114-5118

Huber H, Burggraf S, Mayer T, Wyschkony I, Rachel R, Stetter KO (2000) Ignicoccus gen. nov., a novel genus of hyperthermophilic, chemolithoautotrophic Archaea, represented by two new species, Ignicoccus islandicus sp. nov. and Ignicoccus pacificus sp. nov. Int J Syst Evol Microbiol 50:2093-2100

Huber H, Hohn MJ, Rachel R, Fuchs T, Wimmer VC, Stetter KO (2002) A new phylum of Archaea represented by a nanosized hyperthermophilic symbiont. Nature 417:63-67

Huber H, Gallenberger M, Jahn U, Eylert E, Berg IA, Kockelkorn D, Eisenreich W, Fuchs G (2008) A dicarboxylate/4-hydroxybutyrate autotrophic carbon assimilation cycle in the hyperthermophilic Archaeum Ignicoccus hospitalis. Proc Natl Acad Sci USA 105:7851-7856

Jahn U, Summons R, Sturt H, Grosjean E, Huber H (2004) Composition of the lipids of Nanoarchaeum equitans and their origin from its host Ignicoccus sp. strain KIN4/I. Arch Microbiol 182:404-413

Jahn U, Huber H, Eisenreich W, Hügler M, Fuchs G (2007) Insights into the autotrophic $\mathrm{CO}_{2}$ fixation pathway of the archaeon Ignicoccus hospitalis: comprehensive analysis of the central carbon metabolism. J Bacteriol 189:4108-4119

Jahn U, Gallenberger M, Paper W, Junglas B, Eisenreich W, Stetter KO, Rachel R, Huber H (2008) Nanoarchaeum equitans and Ignicoccus hospitalis: new insights into a unique, intimate association of two Archaea. J Bacteriol 190:1743-1750

Jensen GJ, Briegel A (2007) How electron cryotomography is opening a new window onto prokaryotic ultrastructure. Curr Opin Struct Biol 17:260-267

König H, Rachel R, Claus H (2007) Proteinaceous surface layers of Archaea: ultrastructure and biochemistry. In: Cavicchioli R (ed) Archaea-molecular and cellular biology. ASM Press, Washington, pp 315-340

Kürner J, Frangakis AS, Baumeister W (2005) Cryo-electron tomography reveals the cytoskeletal structure of Spiroplasma melliferum. Science 307:436-438

Li Z, Trimble MJ, Brun YV, Jensen GJ (2007) The structure of FtsZ filaments in vivo suggests a force-generating role in cell division. EMBO J 26:4694-4708

Löwe J, van den Ent F, Amos LA (2004) Molecules of the bacterial cytoskeleton. Annu Rev Biophys Biomol Struct 33:177-198 
Lucic V, Förster F, Baumeister W (2005) Structural studies by electron tomography: from cells to molecules. Ann Rev Biochem 74:833865

Ma X, Ehrhardt DW, Margolin W (1996) Colocalization of cell division proteins Ftsz and FtsA to cytoskeletal structures in living Escherichia coli cells by using green fluorescent protein. Proc Natl Acad Sci USA 93:12998-13003

Mastronarde DA (1997) Dual-axis tomography: an approach with alignment methods that preserve resolution. J Struct Biol 120:343-352

McIntosh R, Nicastro D, Mastronarde DA (2005) New views of cells in 3D: an introduction to electron tomography. Trends Cell Biol $15: 43-51$

Medalia O, Weber I, Frangakis AS, Nicastro D, Gerisch G, Baumeister W (2002) Macromolecular architecture in eukaryotic cells visualized by cryoelectron tomography. Science 298:1209-1213

van de Meene AML, Hohmann-Marriott MF, Vermaas WFJ, Roberson RW (2006) The three-dimensional structure of the cyanobacterium Synechocystis sp. PCC 6803. Arch Microbiol 184:259-270

Näther DJ, Rachel R (2004) The outer membrane of the hyperthermophilic archaeon Ignicoccus: dynamics, ultrastructure and composition. Biochem Soc Trans 32:199-203

Näther DJ, Rachel R, Wanner G, Wirth R (2006) Flagella of Pyrococcus furiosus: multifunctional organelles, made for swimming, adhesion to various surfaces, and cell-cell contacts. J Bacteriol 188:6915-6923

Nickell S, Hegerl R, Baumeister W, Rachel R (2003) Pyrodictium cannulae enter the periplasmic space but do not enter the cytoplasm, as revealed by cryo-electron tomography. J Struct Biol 141:34-42

Paper W, Jahn U, Hohn MJ, Kronner J, Näther DJ, Burghardt T, Rachel R, Stetter KO, Huber H (2007) Ignicoccus hospitalis sp. nov., the host of 'Nanoarchaeum equitans'. Int J System Evol Microbiol 57:803-808

Rachel R, Wyschkony I, Riehl S, Huber H (2002) The ultrastructure of Ignicoccus: evidence for a novel outer membrane and for intracellular vesicle budding in an archaeon. Archaea 1:9-18
Rieger G, Rachel R, Hermann R, Stetter KO (1995) Ultrastructure of the hyperthermophilic archaeon Pyrodictium abyssi. J Struct Biol 115:78-87

Rieger G, Müller K, Hermann R, Stetter KO, Rachel R (1997) Cultivation of hyperthermophilic archaea in capillary tubes resulting in improved preservation of fine structures. Arch Microbiol 168:373-379

Rosenshine I, Tchelet R, Mevarech M (1989) The mechanism of DNA transfer in the mating system of an archaebacterium. Science 245:1387-1389

Scheffel A, Gruska M, Faivre D, Linaroudis A, Plitzko JM, Schüler D (2006) An acidic protein aligns magnetosomes along a filamentous structure in magnetotactic bacteria. Nature 440:110-114

Stierhof YD, Humbel BM, Hermann R, Otten MT, Schwarz H (1992) Direct visualization and silver enhancement of ultrasmall antibody-bound gold particles on immunolabeled ultrathin resin sections. Scanning Microsc 6:1009-1012

Walther P, Ziegler A (2002) Freeze-substitution of high-pressure frozen samples: the visibility of biological membranes is improved when the substitution medium contains water. J Microscopy 208:3-10

Wang X, Lutkenhaus J (1993) The FtsZ protein of Bacillus subtilis is localized at the division site and has GTPase activity that is dependent upon FtsZ concentration. Mol Microbiol 9:435-442

Waters E, Hohn MJ, Ahel I, Graham DE, Adams MD, Barnstead M, Beeson KY, Bibbs L, Bolanos R, Keller M, Kretz K, Lin X, Mathur E, Ni J, Podar M, Richardson TH, Sutton GS, Simon M, Soll D, Stetter KO, Short JM, Noorderwier M (2003) The genome of Nanoarchaeum equitans: insights into early archaeal evolution and derived parasitism. Proc Natl Acad Sci USA 100:1298412988

Wickert H, Göttler W, Krohne G, Lanzer M (2004) Maurer's cleft organization in the cytoplasm of Plasmodium falciparum-infected erythrocytes: new insights from three-dimensional reconstruction of serial ultrathin sections. Eur J Cell Biol 83:567-582 